\title{
Silver Nanoparticle Exposure Causes Pulmonary Structural Damage and Mitochondrial Dynamic Imbalance in the Rat: Protective Effects of Sodium Selenite
}

This article was published in the following Dove Press journal:

International Journal of Nanomedicine

\begin{abstract}
Wanrui Ma, ${ }^{\mathrm{I}-3}$ Shan $\mathrm{He},{ }^{4}$ Huiyan Ma, ${ }^{4}$ Haifeng Jiang, ${ }^{5}$ Ning Yan, ${ }^{6}$ Lili Zhu, ${ }^{6}$ John J Bang, (iD ${ }^{3}$ P Andy Li, ${ }^{2}$ Shaobin Jia ${ }^{6}$

'Department of General Medicine, General Hospital of Ningxia Medical University, Yinchuan, Ningxia, People's Republic of China; ${ }^{2}$ Department of Pharmaceutical Sciences, Biomanufacturing Research Institute and Technological Enterprise (BRITE), North Carolina Central University, Durham, NC, USA; ${ }^{3}$ Department of Environmental, Earth and Geospatial Sciences, North Carolina Central University, Durham, NC, USA; ${ }^{4}$ School of Clinical Medicine, Ningxia Medical University, Yinchuan, Ningxia, People's Republic of hina; ${ }^{5}$ Department of Pathology, General Hospital of Ningxia Medical University, Yinchuan, Ningxia, People's Republic of China; ${ }^{6} \mathrm{Heart}$ Centre, General Hospital of Ningxia Medical University, Yinchuan, Ningxia, People's Republic of China
\end{abstract}

Correspondence: P Andy Li

Department of Pharmaceutical Sciences, Biomanufacturing Research Institute and Technological Enterprise (BRITE), North Carolina Central University, I80 I Fayetteville Street, Durham, NC 27707. USA

Tel + I 9195306872

$\mathrm{Fax}+\mid 9195306600$

Email pli@nccu.edu

Shaobin Jia

Heart Centre, General Hospital of Ningxia Medical University, 804 Shengli South Street, Xingqing District, Yinchuan 750004, People's Republic of China Tel +86 I399507 8969

Email jsbxn@I63.com
Background: With the increased application of Silver nanoparticles (AgNP), its potential concerns to the health of human beings remain to be defined. This study aims to explore the harmful effects of AgNP on lung tissue in animals and to examine the mechanisms of protection achieved by sodium selenite.

Methods: Sprague-Dawley(SD) rats were exposed to AgNP (200 $\mu \mathrm{L}, 1 \mathrm{mg} / \mathrm{mL})$ through a single intratracheal instillation. Sodium selenite $(0.2 \mathrm{mg} / \mathrm{kg})$ was i.p. injected. Malondialdehyde (MDA) and glutathione (GSH) were measured using a spectrophotometer. Histological outcomes and ultrastructural changes were assessed by hematoxylin and eosin (HE) staining and electronic microscopy. Caspases and mitochondrial fission and fusion markers were measured by Western blotting.

Results: The histopathologic findings showed that AgNP significantly increased the thickness of alveolar septa, accumulation of macrophage, and the formation of pulmonary bullae and pulmonary consolidation. Ultrastructural studies showed localization of AgNP inside the mitochondria, hyperplasia and vacuolation of type I and type II alveolar cells, lysis of osmiophilic lamellar bodies, and swollen of the mitochondria. AgNP elevated MDA and reduced GSH levels. AgNP activated caspases-3, increased mitochondrial fission markers Dynamin-related protein 1 (Drp1) and phospho-Drp1(p-Drp1), and decreased fusion proteins optic atrophy 1 (Opa1) and mitofusins 2 (Mfn2). Treatment with sodium selenite for 7 days corrected the AgNP-caused alterations in morphological, ultrastructural, oxidative stress, caspase-3 activation and mitochondrial dynamic imbalance.

Conclusion: We conclude that the exposure of AgNP causes lung tissue damage by enhances oxidative stress, activates caspases-3, and triggers mitochondrial dynamic imbalance towards fission. Sodium selenite effectively detoxifies the AgNP-induced damage to the lung tissue by preventing the above alterations.

Keywords: silver nanoparticle, selenium, pulmonary, mitochondrial dynamics, mitochondrial morphology

\section{Introduction}

In recent years, silver nanoparticle (AgNP) is utilized in a broad spectrum from commercial goods to antimicrobial or treatment agents for diseases. ${ }^{1,2}$ A huge amount of AgNP is produced every year, the maximum estimation of the production in the United States was as high as 20 tons per year. ${ }^{3}$ The occupational and environmental exposure risk of AgNP has increased with the increase of the production and usage, 
causing potential concerns to human health and ecosystems. There are multiple routes of exposure to AgNP, while inhalation has been proposed as the most common route. Studies have indicated that AgNP induces pulmonary toxicity, includes the particle deposition in the lung, pulmonary inflammation, and cause the reduction of pulmonary volume. $^{4-6}$ The possible mechanisms of AgNP toxicity involved DNA damage, mitochondrial toxicity, reactive oxygen species (ROS) accumulation, activations of ROSdependent and independent cell signaling pathways, and inflammatory responses. ${ }^{7-11}$ AgNP can interact with the mitochondria, which means the mitochondria are likely to be the intracellular target of AgNP toxicity.

In general, the mitochondria are highly dynamic organelles, they are in the dynamic balance of fission and fusion, in order to maintain their size, shape, and distribution, which are crucial for organismal health. Mitochondria fission is the process that one mitochondrion divided into two daughter mitochondria, which is regulated by a distinct set of proteins. Drp1 plays a central role in fission, or at least the best understood fission protein, that regulates mitochondrial fission in mammals together with mitochondrial fission protein 1 (Fis1). ${ }^{12,13}$ Mitochondrial fusion is a process where two mitochondria merged into one. The mitochondrial fusion is driven by a two-step process with the outer mitochondrial membrane fusion mediated by Mfn1 and Mfn2 followed by inner membrane fusion, mediated by Opa1. ${ }^{14}$ We have previously shown that AgNP exposure increases ROS production, suppresses mitochondrial membrane potential, elevates mitochondrial oxygen consumption and activates caspase- 3 in a neuronal cell line. ${ }^{15}$ However, there are few in vivo studies on its mitochondrial toxicity, especially the effect of AgNP on mitochondrial dynamics and the evidence AgNP being translocated to mitochondria. Our current study will focus on these points.

Selenium is an essential micronutrient, known for its detoxification effects in heavy metal exposure. ${ }^{16}$ Selenium is a central component of various antioxidant enzymes catalytic sites, such as glutathione peroxidases and thioredoxin reductase, ${ }^{17,18}$ and it is capable of restoring the activity of these enzymes. ${ }^{19-21}$ Selenium can effectively counteract free radicals and protects the structure and function of proteins, DNA, and chromosomes against the injury of oxidation. ${ }^{22}$ Studies have shown that selenium is capable of reducing ROS production. ${ }^{23,24}$

A recent study has shown that the hepatotoxicity of AgNP may be related to the antagonistic effect of silver on the status of essential trace element selenium ${ }^{25}$ and selenium supplementation attenuates hepatotoxicity. ${ }^{10}$ Further, selenium possesses significant potential in protecting against AgNP induced testicular toxicity and inflammation. ${ }^{11} \mathrm{We}$ have previously demonstrated that selenium improves mitochondrial stress, inhibits caspase- 3 activation and reduces cell death induced by AgNP. ${ }^{15}$ In the present study, we aimed to study the detrimental impact of AgNP on the respiratory system and rescuer effects of sodium selenite with the focus on mitochondrial ultrastructural changes and mitochondrial dynamics.

\section{Materials and Methods Silver Nanoparticle Preparation and Characterization}

Silver Powder was purchased from US Research Nanomaterials, Inc (Houston, TX; 20nm, Product Number: US1038). Before administration, AgNP was suspended in $0.9 \% \mathrm{NaCl}$ to prepare stock suspension $(1 \mathrm{mg} / \mathrm{mL})$. The stock suspension was sonicated in an ice bath at $22 \pm 4^{\circ} \mathrm{C}$ room temperature for $30 \mathrm{~min}$ before intratracheal instillation. Transmission electron microscopic examination (TEM, Hitachi H-7650, Tokyo, Japan) was performed for physical characterization.

\section{Animal Experiments}

The specific pathogen-free (SPF) male SD rats, weighing 180-220 grams, at 6-8 weeks of age were purchased from Animal Center of Ningxia Medical University. The rats were housed three in each cage in an institutional animal facility with controlled room temperatures $\left(22 \pm 4^{\circ} \mathrm{C}\right)$ and humidity (30-70\%) under a $12 \mathrm{hrs} \mathrm{light/dark.} \mathrm{Standard} \mathrm{rodent} \mathrm{chow}$ and sterile water were provided ad libidum. A one-week acclimatization period was allowed before the experiment. All animal surgical procedures were performed in strict accordance with the Guide for Laboratory Animal Care and Use and approved by the Institutional Review Board of the General Hospital of Ningxia Medical University (approval numbers 2016-089).

The AgNP stock suspension ( $200 \mu \mathrm{L}$ of $1 \mathrm{mg} / \mathrm{mL})$ was delivered to the rats by intratracheal instillation followed by $500 \mu \mathrm{L}$ of air. The actual dose admitted to each rat was $200 \mu \mathrm{g}$. This dose was selected according to published reports. ${ }^{26}$ All rats were anesthetized with an i.p. injection of $10 \%$ chloral hydrate $(0.3-0.4 \mathrm{~mL} / 100 \mathrm{~g} \mathrm{BW})$ on the 21 st day after intratracheal instillation. After well anesthetized, body weight was recorded, and the lung tissues were carefully removed and washed in ice-cold saline solution, 
dried with regular filter, and then weighted. The lung coefficient was calculated as the ratio of lung tissue weight to the body weight of each individual rat.

The design of the animal experiment is shown in Figure 1 . The rats were randomly divided into four groups ( $\mathrm{n}=10$ in each group): 1) Control group with a single intratracheal instillation of $200 \mu \mathrm{L}$ of $0.9 \% \mathrm{NaCl}$ and intraperitoneal injection of $0.9 \% \mathrm{NaCl}$ once a day for 7 days; 2) AgNP-treated group with a single intratracheal instillation of $200 \mu \mathrm{L}$ of $1 \mathrm{mg} / \mathrm{mL}$ AgNP, and intraperitoneal injection of $0.9 \% \mathrm{NaCl}$ once a day for 7 days; 3) Setreated group with a single intratracheal instillation of 200 $\mu \mathrm{L} 0.9 \% \mathrm{NaCl}$ and intraperitoneal admission of $0.2 \mathrm{mg} / \mathrm{Kg}$ body weight of sodium selenite once a day for 7 days; and 4) $\mathrm{Se}+\mathrm{AgNP}$-treated group with a single intratracheal instillation of $200 \mu \mathrm{L}$ of $1 \mathrm{mg} / \mathrm{mL}$ AgNP and intraperitoneal injection of $0.2 \mathrm{mg} / \mathrm{Kg}$ sodium selenite once a day for 7 days initiated from the same time of AgNP instillation.

\section{Biochemical Analysis}

To measure the oxidative stress in animals, the blood sample was collected and serum was centrifuged for $15 \mathrm{~min}$ at $3000 \mathrm{rpm}$. Levels of MDA, a degradation product of lipid peroxide and GSH, an antioxidant, were measured using commercially available kits (HY-60003 and HY-60006, Beijing Sino-UK Institute of Biological Technology). The MDA was read at $532 \mathrm{~nm}$ and GSH at $412 \mathrm{~nm}$ wavelengths in a spectrophotometer.

\section{Histopathology}

Part of the lung tissues was fixed in $10 \%$ neutral formalin solution overnight and was sliced into small pieces, dehydrating in ascending concentrations of alcohol and clearing in xylene. The tissues were embedded in paraffin blocks and sectioned on a rotary microtome at a thickness of $5 \mu \mathrm{m}$. The sections were stained with hematoxylin and eosin using standard procedure and mounted with coverslips. The

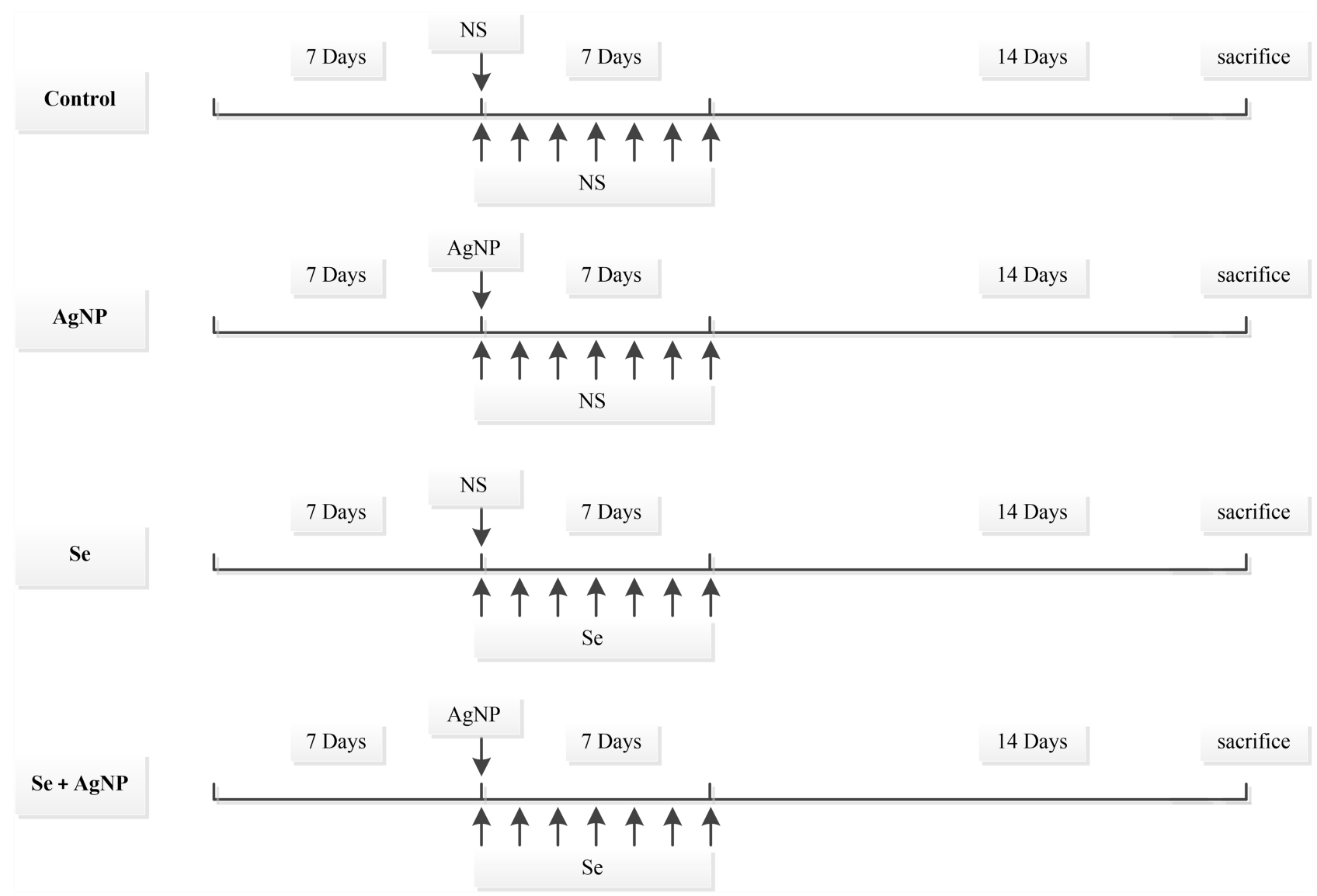

Figure I Experimental design and animal groups. Animals were instilled with single dose of $200 \mu \mathrm{L}$ of I $\mathrm{mg} / \mathrm{mL} \mathrm{AgNP}$ or $200 \mu \mathrm{L} \mathrm{NS}$ into the trachea. Sodium selenite $(0.2 \mathrm{mg} /$ $\mathrm{Kg}$ ) or NS (I mL) were IP injected daily for 7 days immediately following the AgNP intratracheal instillation. Control group, NS intratracheal instillation with NS IP injection; AgNP group, AgNP instillation with NS IP injection; Selenite control group (Se), NS intratracheal instillation with selenite IP injection; AgNP with selenite treatment group (Se+AgNP), AgNP intratracheal instillation plus selenite IP injection. Ten rats per group. All rats were sacrificed on the 2 Ist day after intratracheal instillation.

Abbreviations: AgNP, silver nanoparticle; IP, intraperitoneal injection; NS, normal saline; Se, sodium selenite. 
microscopic images were captured using the Olympus optical microscope (OLYMPUS BX43, Tokyo, Japan) with the purpose of evaluating the overall structural changes. All histopathologic assessments were performed by a pathologist who was blind to the experimental groups.

\section{Transmission Electron Microscopy Examination}

Transmission electron microscopy(TEM) examination was performed according to the standard laboratory protocols. Lung tissues were fixed in $2 \%$ glutaraldehyde for $2 \mathrm{hrs}$. They were washed with $0.1 \mathrm{M}$ dimethyl sodium arsenate three times at $2 \mathrm{~h}$ intervals, then post-fixed in $4 \%$ osmic acid for $2 \mathrm{hrs}$, and then wash with $0.1 \mathrm{M}$ dimethyl sodium arsenate two times. The tissues were dehydrated in ascending concentrations of alcohol. All the above processes were carried out at $4^{\circ} \mathrm{C}$. The tissues were permeated in propylene oxide and embedded in epoxy resin. The resin was polymerized for $48 \mathrm{hrs}$ under $60^{\circ} \mathrm{C}$. Ultrathin sections were cut using a diamond knife and were stained with both uranyl acetate and lead citrate. Observations were carried out and the images were captured using a TEM (Hitachi H-7650, Tokyo, Japan).

\section{Western Blot}

Another part of the lung tissue was frozen in liquid nitrogen immediately after being taken out from the body and stored at $-80^{\circ} \mathrm{C}$. The tissues were homogenized and total protein and mitochondrial protein was extracted using the total protein extraction kit from KeyGEN BioTECH (KGP2100) and the mitochondrial protein extraction kit (KGP8100) according to the instructions of the kits. All processes were carried out in an ice water bath. Protein concentration from each sample was determined using a Microplate BCA Protein Assay Kit (KeyGEN BioTECH, KGP8100). Equal amounts of protein were loaded for electrophoresis. The proteins were transferred to a nitrocellulose membrane (Invitrogen) and blocked for nonspecific binding with $10 \%$ skim milk. The membrane was incubated with primary antibodies solution overnight at $4{ }^{\circ} \mathrm{C}$. The following primary antibodies were used: Cleaved-Caspase 3 (1:500, ab49822, Abcam), Drp1 (1:1000, ab184247, Abcam), p-Drp1 (Ser616 1:1000, 3455, Cell Signaling), Fis1 (1:1000, GTX111010, GeneTex), Opa1 (1:1000, ab157457, Abcam), Mfn2 (1:1000, ab124773, Abcam), GAPDH (1:1000,sc-1616, Santa Cruz Biotechnology, CA, USA) and VDAC (1:1000, GTX114187, GeneTex). Horseradish peroxidase-labeled secondary antibodies were incubated for $1 \mathrm{~h}$ at room temperature. Then the bands were detected using the Pierce ECL Western Blotting Substrate. The GAPDH or VDAC bands served as an internal control, then the ratios of the targeted protein bands and loading control were calculated.

\section{Statistical Analysis}

All data were presented as the means \pm standard deviation (SD), and analyzed by Two-way ANOVA. The figures were prepared using GraphPad Prism 5 for windows. Results with $\mathrm{p}<0.05$ were considered to be statistically significant.

\section{Results}

\section{Characterization of Silver Nanoparticles}

The Energy Dispersive X-Ray Spectroscopy (EDX) and TEM were used to determine the element property and size of AgNP as shown in Figure 2. The results showed the AgNP was almost monodispersed and the diameter was approximately $10-20 \mathrm{~nm}$. The EDX verified the main component of the sample was $\mathrm{Ag}$ and measured its Crystalline/metallic characteristics.

\section{Assessment of Body Weight and Lung Coefficient}

The body weight and lung coefficient of each rat were weighted and compared among the 4 different experimental groups. As shown in Figure 3, the body weights were 180.1$220.3 \mathrm{~g}$ at the beginning of the experiment and increased to $341.7-435.1 \mathrm{~g}$ after 28 days in all animals with no significant differences among the groups $(\mathrm{F}=1.090, \mathrm{p}=0.370)$. Similarly, the lung coefficient was $(3.83-4.72) * 10-3$ in all animals, there no significant differences among the groups $(\mathrm{F}=0.743$, $\mathrm{p}=0.547)$.

\section{Effects on MDA and GSH Levels}

As shown in Figure 4, intra-tracheal instillation of AgNP induced a significant increase in the level of MDA compared to the control group $(\mathrm{P}<0,05)$ and treatment with selenite reduced the MDA level back to baseline. AgNP exposure resulted in a significant decrease in GSH compared to the control group $(\mathrm{P}<0,05)$. However, the treatment of selenite in AgNP exposed rats brought the GSH level back to normal.

\section{Histopathologic Findings}

Pulmonary histopathological changes were observed by HE staining and representative photomicrographs are given in Figure 5. In the control animals with or without selenite 
A

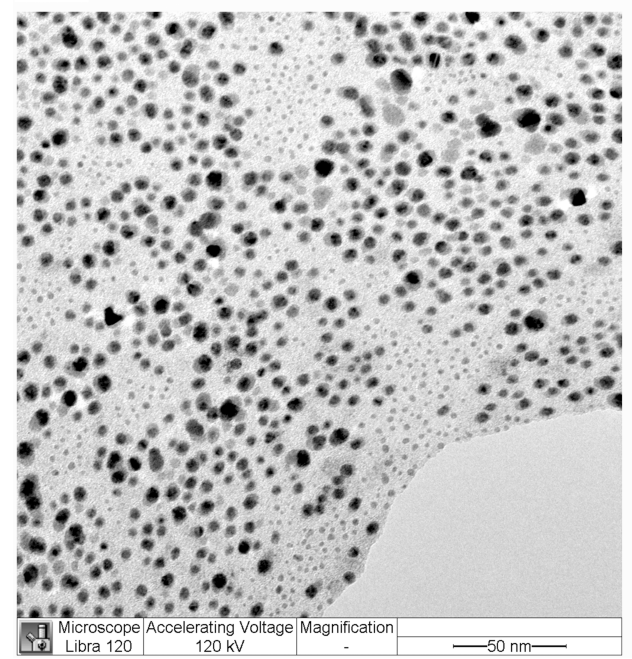

B

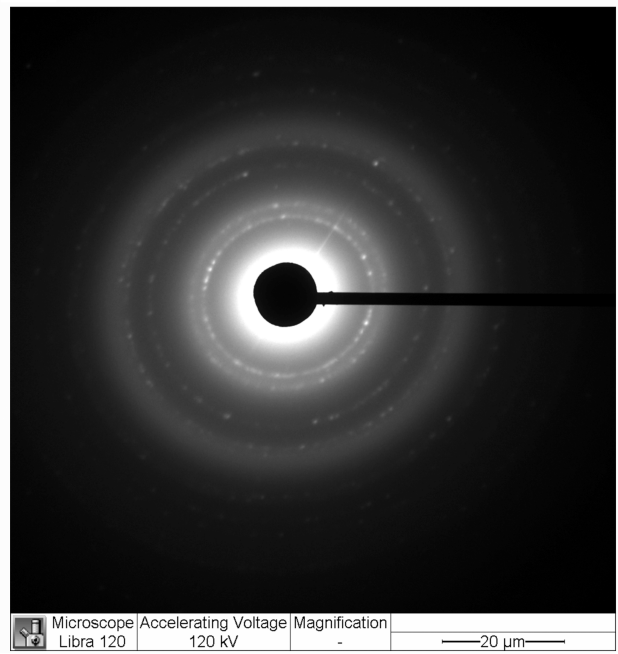

Figure 2 Characterization of powdery siler nanoparticles with TEM (A) and EDX Crystalline/metallic analysis (B). Abbreviations: TEM, Transmission electron microscopy; EDX, energy dispersive X-Ray spectroscopy.

A

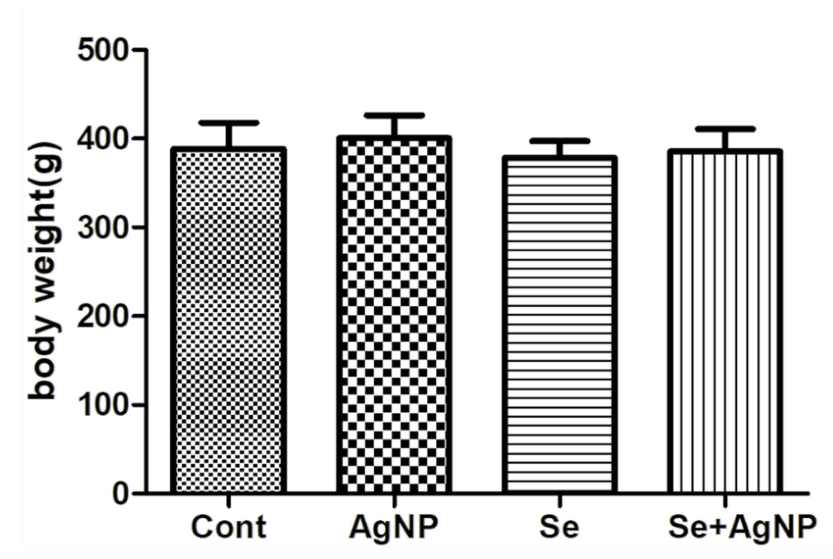

B

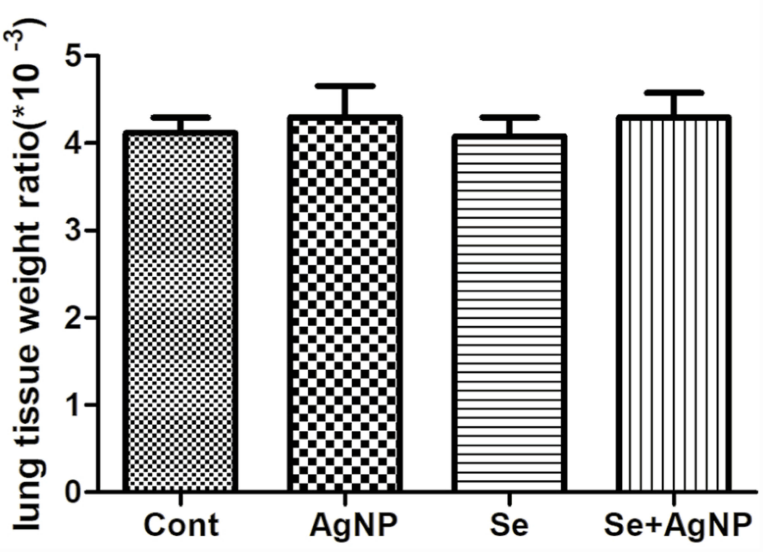

Figure 3 The assessment of body weight $(\mathbf{A})$ and the lung coefficient ratio (B).

Notes: The data represent means \pm SD. $p<0.05$ were considered to be statistically significant.

Abbreviations: Cont, control; AgNP, silver nanoparticle; Se, selenium; SD, standard deviation.

treatment, the bronchi (black arrows in Figure 5A and $\mathrm{B}$ ) and alveolar cavities (yellow arrows in Figure 5A and B) of the lungs were clearly visible, the alveolar wall (red arrows in Figure 5A and B) was intact with no evidence of inflammatory cell infiltration, and alveolar septal connections were reticulum. The AgNP-treated group showed alveolar septal thickening and alveolar cavity reduction (red arrows in Figure 5C) and abundant increased alveolar macrophage accumulation (green arrows in Figure 5C) and formation of localized pulmonary consolidation (Figure 5E). In the AgNP-treated group, near the visceral pleura, the terminal respiratory bronchioles or alveolar cavity fuse to form the pulmonary bullae (yellow arrows in Figure 5C). In the Se+
AgNP-treated group, alveolar septal and alveolar cavity return to normal (yellow arrows in Figure 5D) and alveolar macrophage significantly decreased. Selenite treatment to AgNP exposed animals decreased the thickness of alveolar septum(red arrows in Figure 5D) and alleviated pulmonary consolidation (Figure 5F).

\section{Ultrastructural Changes of Lung Tissue and Mitochondrial Morphology}

The effects of AgNP exposure on lung ultrastructure and mitochondrial morphology were observed via TEM. There were significant differences in the ultrastructure of lung 
A

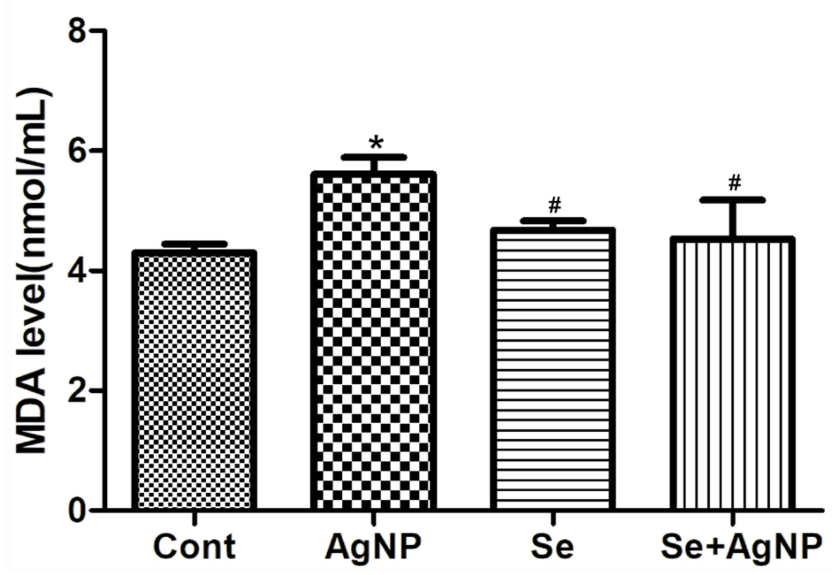

B

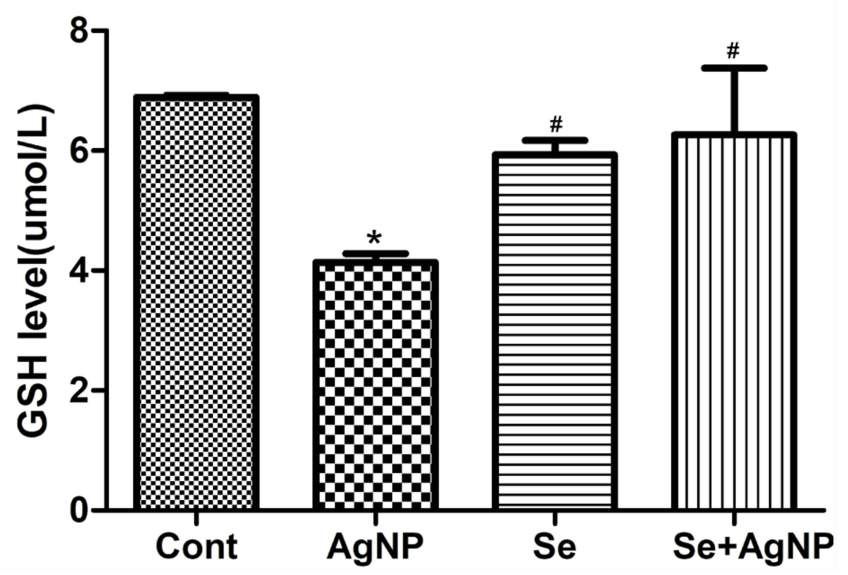

Figure 4 The levels of MDA (A) and GSH (B).

Notes: The data represent means \pm SD. $p<0.05$ were considered to be statistically significant. $* p<0.05$ vs control; \#p<0.05 vs AgNP.

Abbreviations: MDA, Malondialdehyde; GSH, Glutathione; Cont, control; AgNP, silver nanoparticle; Se, selenium; SD, standard deviation.

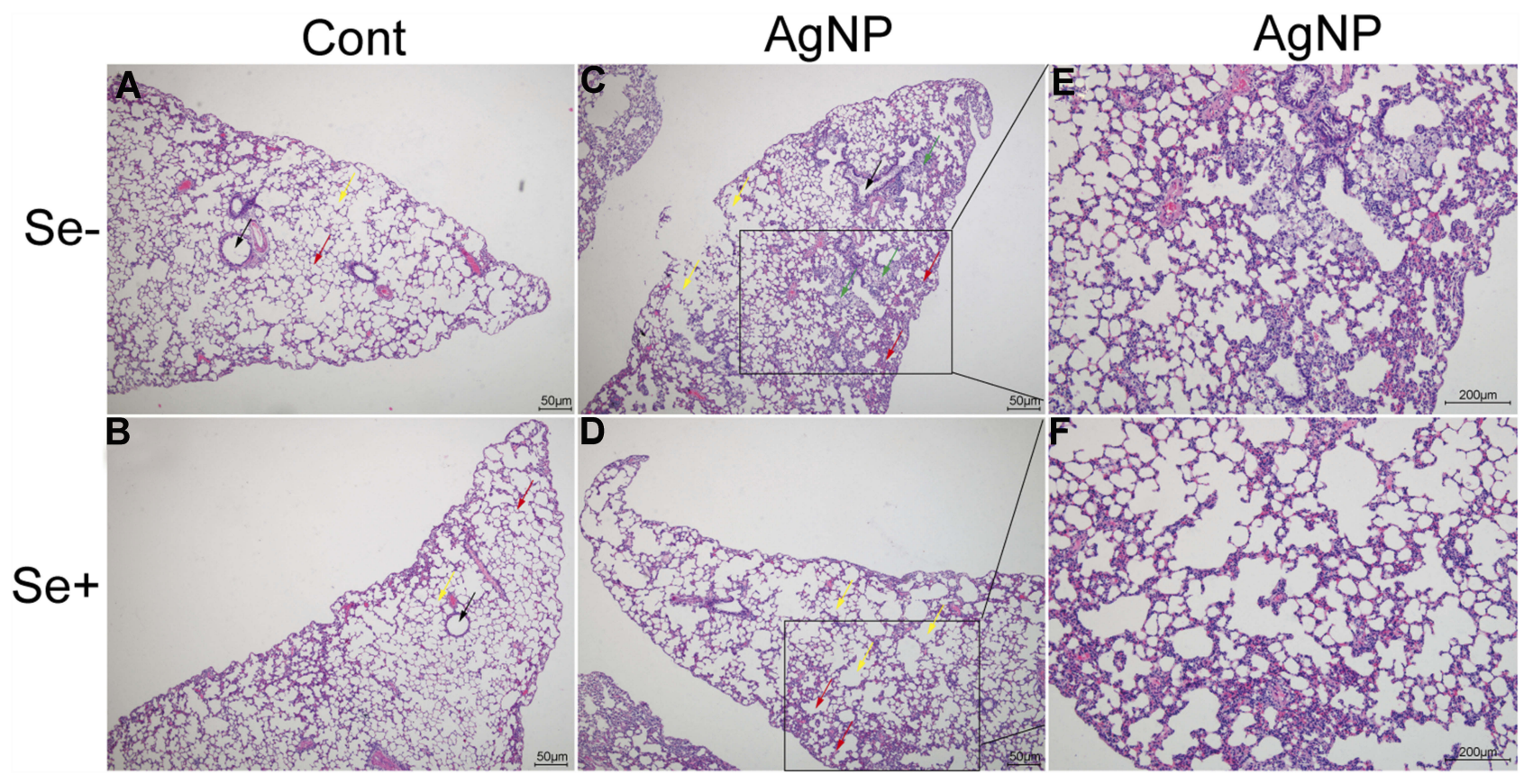

Figure 5 Histological outcomes examined after 21 days of treatment in non-selenium treated (A, C, E) and selenium treated animals (B, D, F). Magnification is $40 \times$ in (A-D) and 100x in (E and F). Black arrows, bronchi; yellow arrows, alveolar cavities; red arrows, alveolar wall; green arrows, alveolar macrophage.

Abbreviations: Cont, control; AgNP, silver nanoparticle; Se, selenium.

tissue between the control and AgNP-treated groups. As shown in Figure 6, the type I and type II alveolar cells were normal in the control and Se-treated groups. In the AgNPtreated group, type I and type II alveolar cell body bigger than those in non-AgNP treated animal samples and a large number of nucleus-free vacuoles were observed (red arrows in Figure 6C). These changes were mitigated in the Setreated AgNP-exposed group. The cell surface microvilli (green arrow), the nuclear of alveolar type II epithelial cell (purple Arrows), osmiophilic lamellar bodies (orange arrows) and ultrastructure of the mitochondria (blue arrows) were shown in Figure 7. As the Figure 7C showed, in AgNP exposure animals, the microvilli on the cell surface were rare (green arrow), the nucleus was agglomerated and condensed (purple arrow), osmiophilic lamellar bodies fusion and lamellar-body vacuolation were presented (orange 


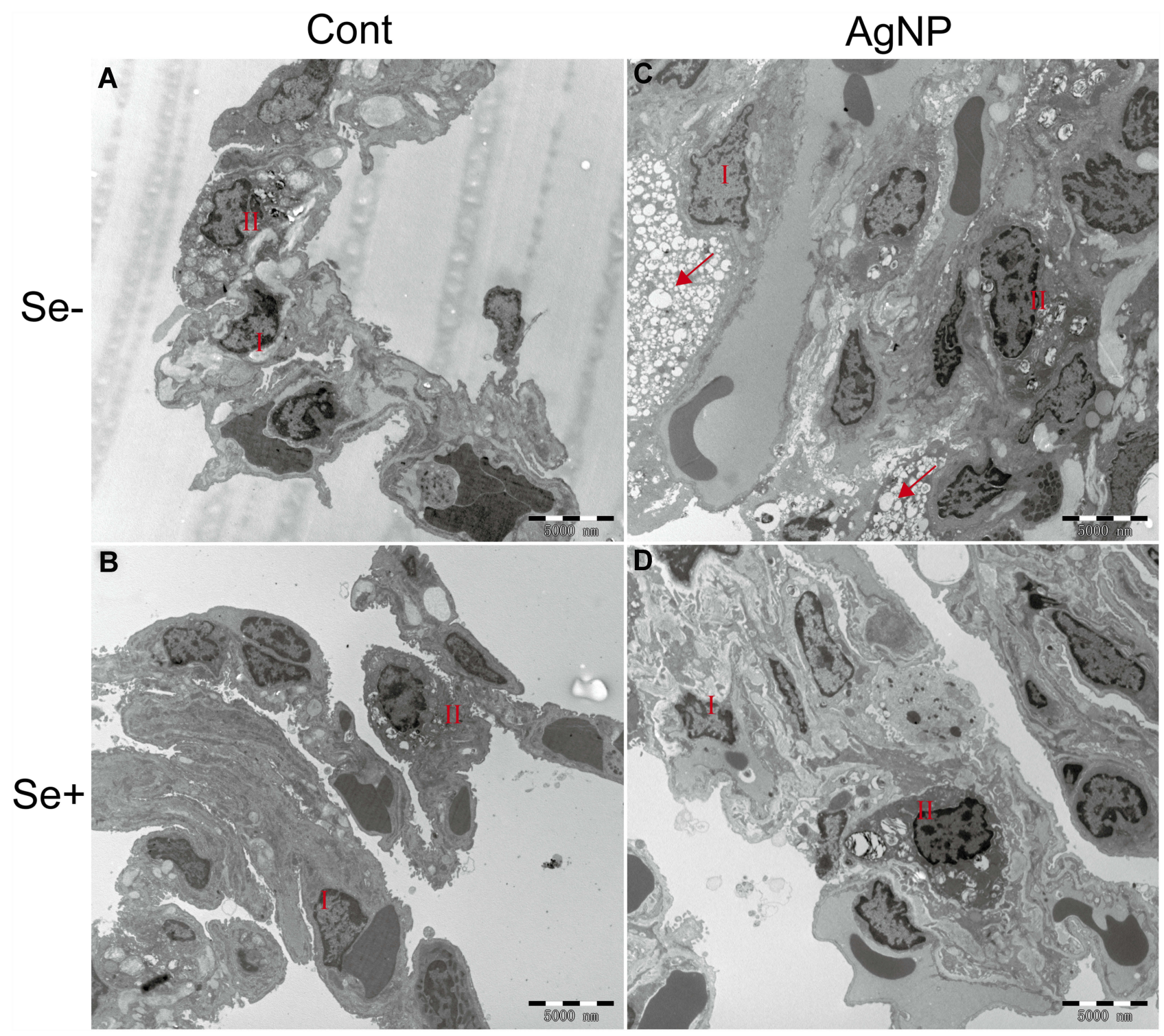

Figure 6 Ultrastructural changes in the lung tissue. (A-D) were the TEM image at 5000x. I, the type I alveolar cell; II, the type II alveolar cell; red arrow, nucleus-free vacuole.

Abbreviations: Cont, control; AgNP, silver nanoparticle; Se, selenium; TEM, Transmission electron microscopy.

arrow), mitochondria were deformed with disrupted or disintegrated cristae (blue arrow). AgNP particles were founded within the pulmonary mitochondria (red arrows) and outside of the mitochondria (dark blue arrows). According to the ruler(red ruler in Figure $7 \mathrm{C}$ and $\mathrm{G}$ ), the diameter of AgNP was around 20-40nm. In selenite-treated AgNP-exposed animals, the mitochondrial cristae become dense and the other above described AgNP-induced changes returned to normal in the lung tissue. Strikingly, AgNP were agglomerated (Figure $7 \mathrm{~F}$ and $\mathrm{H}$ ) and its accumulation within pulmonary mitochondria was not observed in the $\mathrm{Se}+\mathrm{AgNP}$-treated group which means that selenite protection may be related to the prevention of AgNP transportation to the mitochondria.

\section{AgNP Activates Caspases and Alters Mitochondrial Dynamic Balance}

We have previously shown that AgNP causes mitochondrial stress and selenite counteracts the AgNP-induced stress in cultured neuronal cells. ${ }^{15}$ In this part of the study, we measured apoptotic signaling proteins and mitochondrial fission and fusion markers in samples collected from animal lung tissues. As shown in Figure 8, intra-tracheal instillation of AgNP significantly increased cleaved caspase-3 levels and 


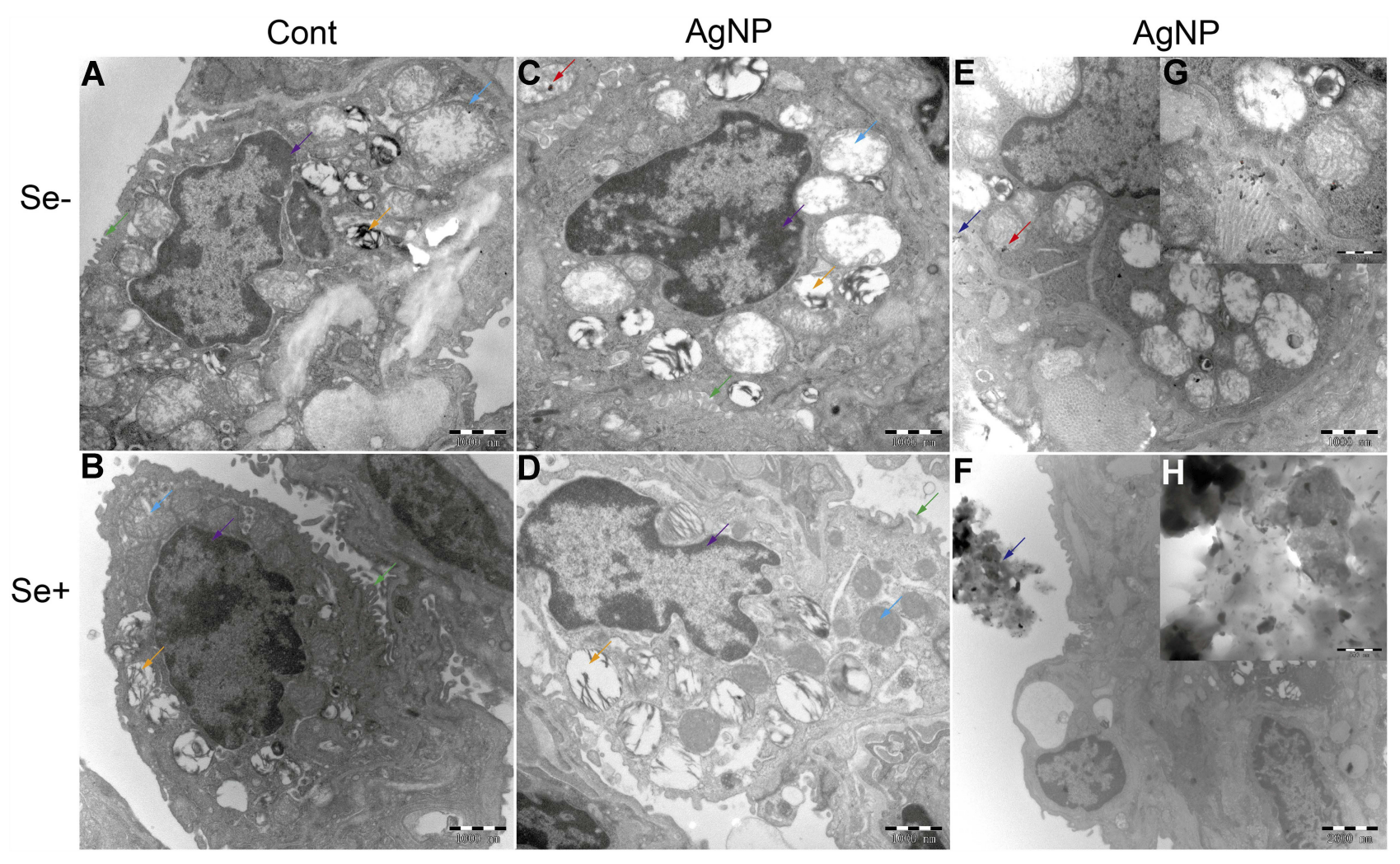

Figure 7 Ultrastructural changes in lung tissue. (A-F) were the TEM image at 20,000x. (G-H) were the zoom-in image at 60,000x. Green arrow, the cell surface microvilli; purple arrows, the nuclear of alveolar type II epithelial cell; orange arrow, osmiophilic lamellar body; blue arrow, mitochondria; red arrow, AgNP within the mitochondria; dark blue arrow, AgNP outside of the mitochondria.

Abbreviations: Cont, control; AgNP, silver nanoparticle; Se, selenium; TEM, Transmission electron microscopy.

treatment with selenite reduced the protein levels back to control values. Further AgNP affected the mitochondrial dynamic balance. Although the increase of fission protein Fis1 has no significance, AgNP exposure markedly increased the fission proteins Drp1, p-Drp1 and decreased the fusion proteins Opa1 and Mfn2. Treatment of selenite in AgNP exposed animals blocked the AgNP induced elevations of total Drp1 and p-Drp1 and reduction of Opa1 and Mfn2 (Figure 8). Selenite also reduced the level of Fis1 in AgNP exposed animal tissue, however it did not reach statistical significance.

\section{Discussion}

The results of the present study have demonstrated that AgNP caused histopathological and ultrastructural changes in the lung tissue, induced mitochondrial damage, oxidative stress and caspases- 3 activation, and increased mitochondrial fission. Intraperitoneal injection of selenium has successfully alleviated AgNP-induced morphological and ultrastructural changes in the lungs and blocked the caspase activation and mitochondrial fission signaling.
The toxicity of AgNP was determined by its physical/ chemical properties, such as size, shape, surface charge. ${ }^{27}$ Thus, we measured the morphology and size of AgNP by the transmission electron microscopic examination. AgNP was almost monodispersed and the diameter was approximately $10-20 \mathrm{~nm}$. Due to $\mathrm{Ag}+$ ions are also related to the cell death, ${ }^{28,29}$ it should be taken into consideration that how many $\mathrm{Ag}+$ ions in the stock suspension made from powdery AgNP. However, it has been demonstrated that endocytosed AgNP were degraded in the lysosomes and released of $\mathrm{Ag}+$ ions in the cytosol caused cell death. ${ }^{27}$ Considering that some silver particles maybe convert into silver ions after entering the body, we did not detect the amount of $\mathrm{Ag}+$ ions in the stock suspension.

It has been demonstrated that AgNP exposure induces oxidative stress, which is postulated to be an important mechanism of cell apoptosis. MDA and GSH are considered a reliable marker of oxidative stress in terms of lipid peroxidation and antioxidation, ${ }^{30}$ therefore the level of MDA and GSH were measured in the present study. The results indicate that the MDA level significantly elevated $\mathrm{d}$ while GSH level decreased in the AgNP group. MDA, 
A

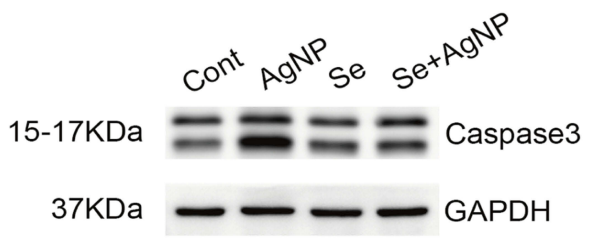

B
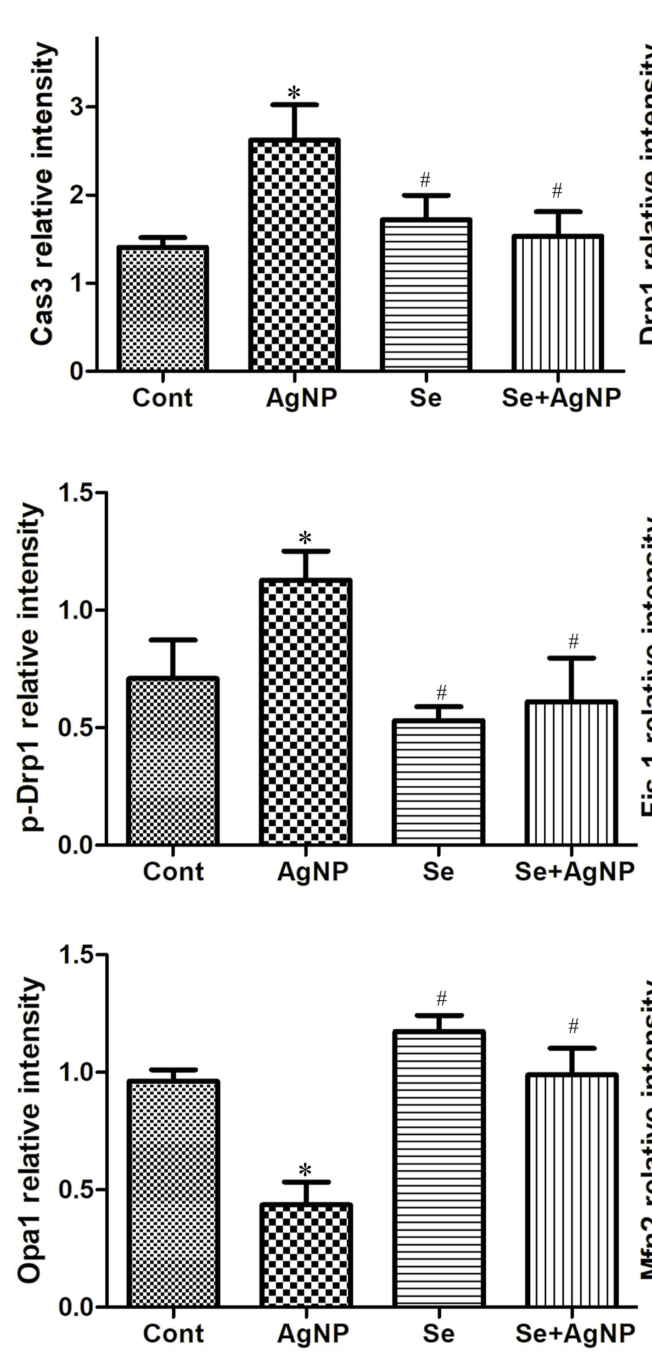
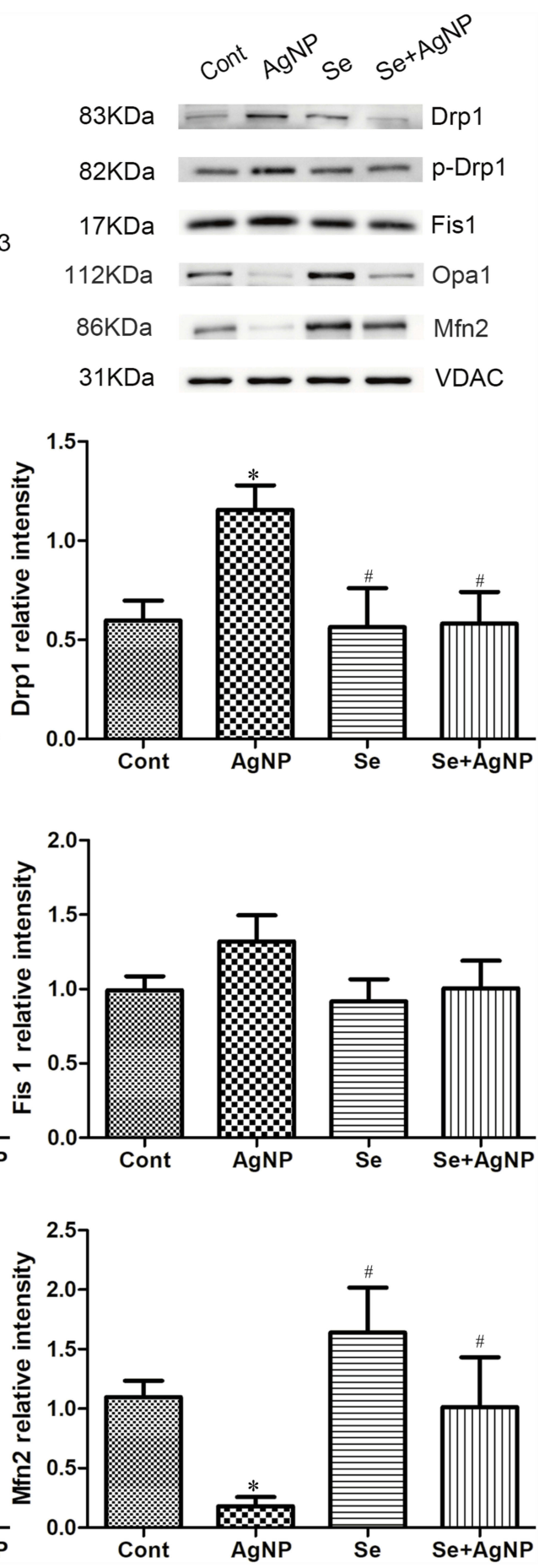

Figure 8 AgNP activates caspase-3 and alters mitochondrial dynamic balance. (A) representative Western blots of each target protein; (B) Bar graphs showing target protein relative levels.

Notes: The data represent means \pm SD. ${ }^{*} \mathrm{p}<0.05$ vs control; ${ }^{*} \mathrm{p}<0.05$ vs AgNP.

Abbreviations: Cont, control; AgNP, silver nanoparticle; Se, selenium; SD, standard deviation.

an end product of lipid peroxidation, can expand the effect of ROS and indirectly represents the level of damage of the cell and tissue. ${ }^{31}$ GSH can clear the superoxide anionfree radicals to protect the cells from being injured, which represents the capacity of clearing free radicals from the organism. The increase of MDA and the decrease of GSH reflected the enhance oxidative stress caused by AgNP exposure. However, selenium treatment reversed the AgNP-induced increase in MDA and decrease in GSH. This is consistent with previous studies showing that 
AgNP induces inflammatory responses as reflected by increased levels of oxidative stress-related factors such as GSH, Superoxide dismutase(SOD), catalase(CAT), glutathione peroxidase (GPx), MDA, interleukin-1 beta(IL$1 \beta)$, IL- 6 , and tumor necrosis factor-alpha(TNF- $\alpha){ }^{10,11}$

A number of studies have shown that the extent of AgNP toxicity in the pulmonary are mostly particle sizedependent, which is closely related to whether AgNP is able to reach the alveoli and to deposit in the lungs. ${ }^{4}$ The smaller sized AgNP was the more apparent toxicity to the cells and tissues. ${ }^{32,33}$ In our study, $20 \mathrm{~nm}$-sized silver nanoparticle powder was used. Although neither AgNP nor selenite affect the body weight and lung tissue weight ratio, the histological data demonstrated that exposure of AgNP resulted in increased thickness of the alveolar septa, reduction of alveoli, rupture of alveolar membranes, and infiltration of inflammatory cells to the lungs, which is consistent to previous reports showing that AgNP caused adverse impact to the lungs varies from minimal pulmonary inflammation to the potential persistence of lung functional and structural deterioration. ${ }^{5,6,34,35}$ Treatment of sodium selenite alleviated the damaging effects of AgNP, suggesting that dietary intake of sodium selenite as a supplement may be beneficial in preventing AgNP exposure induced damage to the lungs. The present results are consistent with previous finding showing that selenium reduces cytotoxicity caused by heavy metals, including AgNP. ${ }^{10,11,36}$

Intratracheal instillation with AgNP (200 $\mu \mathrm{g} / \mathrm{rat})$ resulted in alveolar cell proliferation, vacuoles formation, reduced number of microvilli, osmiophilic lamellar body lysis, mitochondrial lucency, and cristae disarray, disappearance, and swelling. Localization of $\mathrm{Ag}$ particles in the mitochondria was visible in AgNP exposed animal lung tissues. The mitochondrion is an important subcellular organelle responsible for energy production. Mitochondrial cristae are folds of the mitochondrial inner membrane studded with respiratory complexes, ATP synthase and transport proteins such as ADP/ATP carrier and phosphate carrier. ${ }^{37}$ Healthy cristae are very important and necessary for the process of electron transport chain (ETC) and the capacity of ATP generation. Disintegration and mitochondrial swelling cause damage to mitochondrial functional performance and initiate cell death pathways. Due to the limited amount of tissue sample availability, we did not perform the ATP production and ETC enzyme activity measurements. However, a recent study has already shown that AgNP compromised mitochondrial respiratory complex activities in the rat liver. ${ }^{38}$ We have also observed that AgNP impairs the cardiac functional performance, damages myocardial ultrastructure and mitochondria membrane and cristae, causes mitochondrial fission, and activates autophagy (Data will be presented in an upcoming manuscript). Fortunately, treatment with selenite ameliorated AgNP induced ultrastructural damage of the alveolar epithelial cells. Interestingly, there were no mitochondrial located silver particles observed in the selenite treated animals. It is possible that AgNP may directly penetrate into the mitochondria, where they cause mitochondrial structural changes and functional alterations. Selenium prevented the AgNP particles entering the mitochondria.

While the mitochondria are the most important organelles for energy metabolism under physiological condition, they also play critical roles in initiating cell death pathways under pathological conditions. ${ }^{39}$ Damage to the mitochondria could activate the mitochondria-mediated cell death pathways, which involves releases of pro-apoptotic factors such as cytochrome $c$ and second mitochondriaderived activator of caspases (Smac)/direct IAP binding protein with low pI (DIABLO) to the cytosol resulting in activation of caspases, or translocations of apoptosisinducing factor (AIF) and/or endonuclease $\mathrm{G}$ to the nucleus causing DNA damage. ${ }^{39,40}$ Previous studies, including our own, have shown that AgNP exposure resulted in activation of caspase-dependent cell death pathway and suppression of mitochondrial activity in cultured cells. ${ }^{15,41-44}$ In this study, we measured cleaved caspase- 3 in lung tissues of the rats instilled with AgNP. The results showed that AgNP significantly increased the protein levels of cleaved caspases-3, suggesting that the mitochondrial apoptosis pathway has been activated after AgNP exposure in vivo.

Under normal conditions, the mitochondria are in a dynamic equilibrium of fission and fusion, which is facilitated by the intracellular mitochondrial movement. This dynamic process plays an important role not only in regulating the mitochondrial morphology, quantity, subcellular distribution and function of mitochondria, but also in maintaining mitochondria's homeostasis. Excessive fission results in mitochondrial fragmentation which is often linked to mitochondrial dysfunction as this dynamic state predominates during elevated stress and cell death. ${ }^{45}$ Mitochondria fission promotes apoptosis by releasing cytochrome $\mathrm{C}$ under some circumstances, ${ }^{46}$ it can also lead to activation of autophagy and cell death. ${ }^{47}$ Drp1 is the predominant mediator of mitochondrial fission in mammals. ${ }^{48}$ Drp1, once being activated through phosphorylation, binds to Fis 1 to 


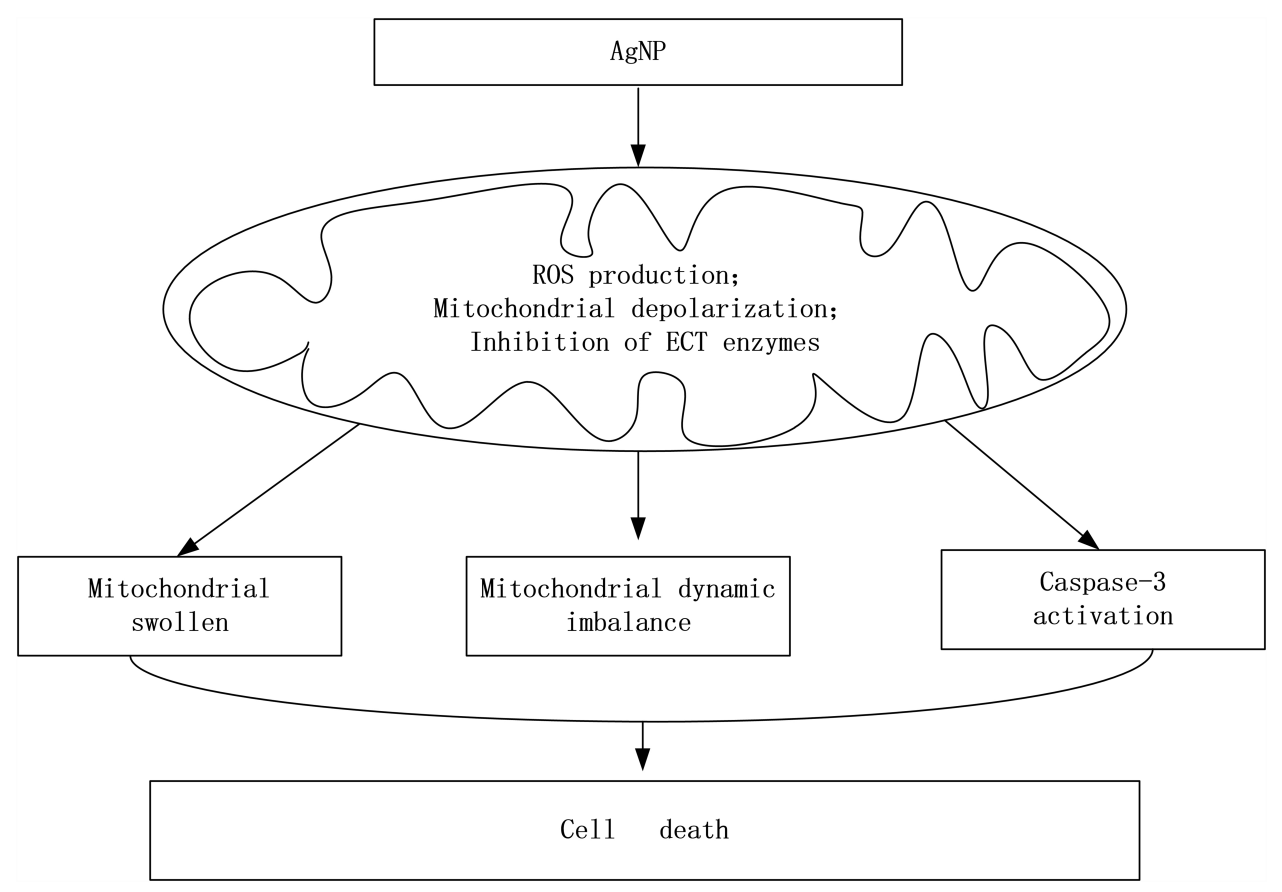

Figure 9 The schematic diagram of the AgNP damage mechanism.

Abbreviations: AgNP, silver nanoparticle; ROS, reactive oxygen species; ECT, electron transport chain.

initiate the mitochondrial fission and eventually fragmentation and cell death. ${ }^{49,50}$ Our present study showed that intratracheal instillation of AgNP to the rats significantly increased the mitochondrial fission proteins Drp1, p-Drp1 (Ser616) and Fis1, suggesting that AgNP induced mitochondrial fission. Mitochondrial fusion and division generally counterbalance each other. If mitochondrial fusion is inhibited, unopposed fission results in mitochondrial fragmentation and some deficiencies such as metabolic substrates or mitochondrial DNA accumulate and lead to cellular dysfunction. $^{51,52}$ Our data showed that the mitochondrial fusion protein Opa1 and Mfn2 were significantly decreased after AgNP exposure. In other words, AgNP not only induced mitochondrial fission but also restrained fusion. Compared with the AgNP group, selenium treatment prevented the activation of mitochondrial fission and inhibition of fusion by bringing the fission and fusion marker down to control values. These results are in agreement with our previous in vivo findings showing that selenium prevents mitochondrial dynamic alteration and improves mitochondrial function in cultured neuronal cells. ${ }^{53,54}$ It is likely that AgNP enters the mitochondria, where it causes increased ROS production which leads to mitochondrial membrane depolarization and ETC inhibition. These events activate cell death pathways, disturb the mitochondrial dynamic balance toward fission and subsequently cause mitochondrial functional and morphological changes that eventually result in cellular damage. A proposed schematic diagram illustrates the AgNP damage mechanism is given in Figure 9.

\section{Conclusion}

Intratracheal instillation of AgNP caused thickening of the alveolar septa, accumulation of macrophages in the alveoli, formation of pulmonary bullae and pulmonary consolidation, disintegration of the mitochondrial cristae, and swelling of the mitochondria. AgNP activated oxidative stress, caspase-3 and mitochondrial fission. Treatment with sodium selenite to the animals prevented the AgNP-caused histological and ultrastructural alterations, blocked caspase-3 activation, and stabilized mitochondrial dynamic balance.

\section{Acknowledgments}

This research was supported by the Natural Science Foundation of China under Grant [number 81660530] and the Ningxia Natural Science Foundation under Grant [number NZ16173] to WM. This study was also partially supported by US NSF-PIRE under Grant [number 1243433] and NSF-EiR under Grant [number 1832134] to JB. Authors also thank J. Wei and his group at the Joint School of Nanoscience and Nanoengineering (JSNN) in Greensboro, N.C. for their electromicropic confirmation on AgNP samples. 


\section{Disclosure}

The authors report no conflicts of interest in this work.

\section{References}

1. Lem KW, Choudhury A, Lakhani AA, et al. Use of nanosilver in consumer products. Recent Pat Nanotechnol. 2012;6(1):60-72. doi:10.2174/187221012798109318

2. Fordhamb WR, Redmond S, Westerland A, et al. Silver as a bactericidal coating for biomedical implants. Surf Coat Technol. 2014;253:52-57. doi:10.1016/j.surfcoat.2014.05.013

3. Hendren CO, Mesnard X, Droge J, et al. Estimating production data for five engineered nanomaterials as a basis for exposure assessment. Environ Sci Technol. 2011;45(7):2562-2569. doi:10.1021/es103300g

4. Braakhuis HM, Cassee FR, Fokkens PH, et al. Identification of the appropriate dose metric for pulmonary inflammation of silver nanoparticles in an inhalation toxicity study. Nanotoxicology. 2016;10 (1):63-73. doi:10.3109/17435390.2015.1012184

5. Braakhuis HM, Gosens I, Krystek P, et al. Particle size dependent deposition and pulmonary inflammation after short-term inhalation of silver nanoparticles. Part Fibre Toxicol. 2014;11:49. doi:10.1186/ s12989-014-0049-1

6. Sung JH, Ji JH, Park JD, et al. Subchronic inhalation toxicity of silver nanoparticles. Toxicol Sci. 2009;108(2):452-461. doi:10.1093/toxsci/ $\mathrm{kfn} 246$

7. Haase A, Rott S, Mantion A, et al. Effects of silver nanoparticles on primary mixed neural cell cultures: uptake, oxidative stress and acute calcium responses. Toxicol Sci. 2012;126(2):457-468. doi:10.1093/ toxsci/kfs003

8. Maurer LL, Meyer JN. A systematic review of evidence for silver nanoparticle-induced mitochondrial toxicity. Environ Sci Nano. 2016;3(2):311-322. doi:10.1039/C5EN00187K

9. Chairuangkitti P, Lawanprasert S, Roytrakul S, et al. Silver nanoparticles induce toxicity in A549 cells via ROS-dependent and ROS-independent pathways. Toxicol in Vitro. 2013;27(1):330-338. doi:10.1016/j.tiv.2012.08.021

10. Ansar S, Alshehri SM, Abudawood M, et al. Antioxidant and hepatoprotective role of selenium against silver nanoparticles. Int J Nanomedicine. 2017;12:7789-7797. doi:10.2147/IJN.S136748

11. Ansar S, Abudawood M, Hamed SS, et al. Sodium selenite protects against silver nanoparticle-induced testicular toxicity and inflammation. Bio Trace Elem Res. 2017;175(1):161-168. doi:10.1007/s12011-016-0759-3

12. Li HN, Zimmerman M, Milledge GZ, et al. Water-soluble coenzyme Q10 reduces rotenone-induced mitochondrial fission. Neurochem Res. 2017;42(4):1096-1103. doi:10.1007/s11064-016-2143-2

13. Chan DC. Fusion and fission: interlinked processes critical for mitochondrial health. Annu Rev Genet. 2012;46:265-287. doi:10.1146/ annurev-genet-110410-132529

14. Tilokani L, Nagashima S, Paupe V, et al. Mitochondrial dynamics: overview of molecular mechanisms. Essays Biochem. 2018;62 (3):341-360. doi:10.1042/EBC20170104

15. Ma W, Jing L, Valladares A, et al. Silver nanoparticle exposure induced mitochondrial stress, caspase- 3 activation and cell death: amelioration by sodium Selenite. Int $J$ Biol Sci. 2015;11 (8):860-867. doi:10.7150/ijbs.12059

16. IKemoto T, Kunito T, Tanaka H, et al. Detoxification mechanism of heavy metals in marine mammals and seabirds: interaction of selenium with mercury, silver, copper, zinc, and cadmium in liver. Arch Environ Contam Toxicol. 2004;47(3):402-413. doi:10.1007/s00244004-3188-9

17. Ralston NV, Raymond LJ. Dietary selenium's protective effects against methylmercury toxicity. Toxicology. 2010;278(1):112-123. doi:10.1016/j.tox.2010.06.004
18. Ma YM, Lbeanu G, Wang LY, et al. Selenium suppresses glutamate-induced cell death and prevents mitochondrial morphological dynamic alterations in hippocampal HT22 neuronal cells. BMC Neurosci. 2017;18(1):15. doi:10.1186/s12868-017-0337-4

19. Islam F, Zia S, Sayeed I, et al. Selenium-induced alteration of lipids, lipid peroxidation, and thiol group in circadian rhythm centers of rat. Biol Trace Elem Res. 2002;90(1-3):203-214. doi:10.1385/ BTER:90:1-3:203

20. Venardos K, Harrison G, Headrick J, et al. Effects of dietary selenium on glutathione peroxidase and thioredoxin reductase activity and recovery from cardiac ischemia-reperfusion. $J$ Trace Elem Med Biol. 2004;18(1):81-88. doi:10.1016/j.jtemb.2004.01.001

21. Panee J, Liu W, Nakamura K, et al. The responses of HT22 cells to the blockade of mitochondrial complexes and potential protective effect of selenium supplementation. Int J Biol Sci. 2007;3 (5):335-341. doi:10.7150/ijbs.3.335

22. Rayman MP. The importance of selenium to human health. Lancet. 2000;356(9225):233-241. doi:10.1016/S0140-6736(00)02490-9

23. Yeo JE, Kang SK. Selenium effectively inhibits ROS-mediated apoptotic neural precursor cell death in vitro and in vivo in traumatic brain injury. Biochim Biophys Acta. 2007;1772(11-12):1199-1210. doi:10.1016/j.bbadis.2007.09.004

24. Zhou YJ, Zhang SP, Liu CW, et al. The protection of selenium on ROS mediated-apoptosis by mitochondria dysfunction in cadmium-induced LLC-PK(1) cells. Toxicol in Vitro. 2009;23 (2):288-294. doi:10.1016/j.tiv.2008.12.009

25. Shipelin VA, Kudan PV, Zgoda VG, et al. Effect of silver nanoparticles on protein composition of rat liver microsomal fraction. Bull Exp Bio Med. 2018;166(1):80-85. doi:10.1007/s10517-018-4293-5

26. Holland NA, Becak DP, Shannahan JH, et al. Cardiac Ischemia reperfusion injury following instillation of $20 \mathrm{~nm}$ citrate-capped nanosilver. J Nanomed Nanotechnol. 2015;6(Suppl 6):006.

27. De Matteis V, Malvindi MA, Galeone A, et al. Negligible particle-specific toxicity mechanism of silver nanoparticles: the role of $\mathrm{Ag}+$ ion release in the cytosol. Nanomedicine. 2015;11 (3):731-739. doi:10.1016/j.nano.2014.11.002

28. Beer C, Foldbjerg R, Hayashi Y, et al. Toxicity of silver nanoparticles —nanoparticle or silver ion? Toxicol Lett. 2012;208(3):286-292. doi:10.1016/j.toxlet.2011.11.002

29. Pratsinis A, Hervella P, Leroux JC, et al. Toxicity of silver nanoparticles in macrophages. Small. 2013;9(15):2576-2584. doi:10.1002/ smll.201202120

30. Chakravarty S, Rizvi SI. Day and night GSH and MDA levels in healthy adults and effects of different doses of melatonin on these parameters. Int J Cell Biol. 2011;2011:404591. doi:10.1155/2011/404591

31. Su L, Wang M, Yin ST, et al. The interaction of selenium and mercury in the accumulations and oxidative stress of rat tissues. Ecotoxicol Environ Saf. 2008;70(3):483-489. doi:10.1016/j.ecoenv.2007.05.018

32. Kim TH, Kim M, Park HS, et al. Size-dependent cellular toxicity of silver nanoparticles. J Biomed Mater Res A. 2012;100(4):1033-1043. doi:10.1002/jbm.a.34053

33. Cho YM, Mizuta Y, Akagi JI, et al. Size-dependent acute toxicity of silver nanoparticles in mice. J Toxicol Pathol. 2018;31(1):73-80. doi:10.1293/tox.2017-0043

34. Stebounova LV, Adamcakova-Dodd A, Kim JS, et al. Nanosilver induces minimal lung toxicity or inflammation in a subacute murine inhalation model. Part Fibre Toxicol. 2011;8(1):5. doi:10.1186/17438977-8-5

35. Song KS, Sung JH, Ji JH, et al. Recovery from silver-nanoparticle exposure-induced lung inflammation and lung function changes in Sprague Dawley rats. Nanotoxicology. 2013;7(2):169-180. doi:10.3109/17435390.2011.648223

36. Abarikwu SO, Adebayo OL, Otuechere CA, et al. Selenium and rutin alone or in combination do not have stronger protective effects than their separate effects against cadmium-induced renal damage. Pharm Biol. 2016;54(5):896-904. doi:10.3109/13880209.2015.1089912 
37. Ruprecht JJ, Kunji ER. Structural changes in the transport cycle of the mitochondrial ADP/ATP carrier. Curr Opin Struct Bio. 2019;57:135-144. doi:10.1016/j.sbi.2019.03.029

38. Teodoro JS, Sliva R, Varela AT, et al. Low-dose, subchronic exposure to silver nanoparticles causes mitochondrial alterations in Sprague-Dawley rats. Nanomedicine (Lond). 2016;11(11):1359-1375. doi:10.2217/nnm2016-0049

39. Green DR, Reed JC. Mitochondria and apoptosis. Science. 1998;281 (5381):1309-1312. doi:10.1126/science.281.5381.1309

40. Ma YM, Guo YZ, Ibeanu G, et al. Overexpression of selenoprotein $\mathrm{H}$ prevents mitochondrial dynamic imbalance induced by glutamate exposure. Int J Bio Sci. 2017;13(11):1458-1469. doi:10.7150/ ijbs. 21300

41. Foldbjerg R, Olesen P, Hougaard M, et al. PVP-coated silver nanoparticles and silver ions induce reactive oxygen species, apoptosis and necrosis in THP-1 monocytes. Toxicol Lett. 2009;190 (2):156-162. doi:10.1016/j.toxlet.2009.07.009

42. Carlson C, Hussain SM, Schrand AM, et al. Unique cellular interaction of silver nanoparticles: size-dependent generation of reactive oxygen species. J Phys Chem B. 2008;112(43):13608-13619. doi:10.1021/jp712087m

43. Singh RP, Ramarao P. Cellular uptake, intracellular trafficking and cytotoxicity of silver nanoparticles. Toxicol Lett. 2012;213 (2):249-259. doi:10.1016/j.toxlet.2012.07.009

44. Foldbjerg R, Dang DA, Autrup H. Cytotoxicity and genotoxicity of silver nanoparticles in the human lung cancer cell line, A549. Arch Toxicol. 2011;85(7):743-750. doi:10.1007/s00204-010-0545-5

45. Zemirli N, Morel E, Molino D. Mitochondrial dynamics in basal and stressful conditions. Int J Mol Sci. 2018;19(2):564. doi:10.3390/ ijms 19020564
46. Mishra P, Chan DC. Mitochondrial dynamics and inheritance during cell division, development and disease. Nat Rev Mol Cell Biol. 2014;15(10):634-646. doi:10.1038/nrm3877

47. Jahani-Asl A, Cheung EC, Neuspiel M, et al. Mitofusin 2 protects cerebellar granule neurons against injury-induced cell death. $J$ Biol Chem. 2007;282(33):23788-23798. doi:10.1074/jbc.M703812200

48. Chang CR, Blackstone C. Dynamic regulation of mitochondrial fission through modification of the dynamin-related protein Drp1. Ann N Y Acad Sci. 2010;1202:34-39. doi:10.1111/j.1749-6632.2010.05629.x

49. van der Bliek AM, Shen Q, Kawajiri S. Mechanisms of mitochondrial fission and fusion. Cold Spring Hard Perspect Biol. 2013;5(6): a011072.

50. Disatnik MH, Ferreira JC, Campos JC, et al. Acute inhibition of excessive mitochondrial fission after myocardial infarction prevents long-term cardiac dysfunction. J Am Heart Assoc. 2013;2(5): e000461. doi:10.1161/JAHA.113.000461

51. Chen H, Detmer SA, Ewald AJ, et al. Mitofusins Mfn1 and Mfn2 coordinately regulate mitochondrial fusion and are essential for embryonic development. $J$ Cell Biol. 2003;160(2):189-200. doi:10.1083/jcb.200211046

52. Chen H, Chomyn A, Chan DC. Disruption of Fusion Results in Mitochondrial Heterogeneity and Dysfunction. $J$ Biol Chem. 2005;280(28):26185-26192. doi:10.1074/jbc.M503062200

53. Kumari S, Mehta SL, Li PA. Glutamate induces mitochondrial dynamic imbalance and autophagy activation: preventive effects of selenium. PLoS One. 2012;7(6):e39382. doi:10.1371/journal.pone.0039382

54. Mendelev N, Mehta SL, Idris H, et al. Selenite stimulates mitochondrial biogenesis signaling and enhances mitochondrial functional performance in murine hippocampal neuronal cells. PLoS One. 2012;7(10):e47910. doi:10.1371/journal.pone.0047910
International Journal of Nanomedicine

\section{Publish your work in this journal}

The International Journal of Nanomedicine is an international, peerreviewed journal focusing on the application of nanotechnology in diagnostics, therapeutics, and drug delivery systems throughout the biomedical field. This journal is indexed on PubMed Central, MedLine, CAS, SciSearch ${ }^{\circledR}$, Current Contents ${ }^{\mathbb{R}} /$ Clinical Medicine,
Journal Citation Reports/Science Edition, EMBase, Scopus and the Elsevier Bibliographic databases. The manuscript management system is completely online and includes a very quick and fair peer-review system, which is all easy to use. Visit http://www.dovepress.com/ testimonials.php to read real quotes from published authors. 